ISSN: 2581-8341

Volume 04 Issue 03 March 2021

DOI: 10.47191/ijesrr/V4-i3-13, Impact Factor: 5.825

IJCSRR@ 2021

www.ijcsrr.org

\title{
Association of Colours and Mood Tones That Could Define Stress among International School Students in Bangkok
}

\author{
Jiraporn Jensuriyarkun ${ }^{1}$, Tita Matrot ${ }^{2}$, Patreeya Janyasan ${ }^{3}$, Dr. Ponlkrit Yeesin ${ }^{4}$ \\ ${ }^{1}$ Harrow International School \\ ${ }^{2}$ Niva American International School \\ ${ }^{3}$ Mahidol University International Demonstration School \\ ${ }^{4}$ Facult of science, Srinakharinwirot University, Bangkok, Thailand
}

\begin{abstract}
Have you ever wondered how colours perceiving through the lens of our eyes influence our emotions or why some objects in different colours dissimilarly affect the mood we experience in our daily lives? The purpose of this study is to determine the correlation between colours and stress levels of international school teenagers. The rationale behind this topic is from theGoethe's Theory of Colours. To test whether two variables correlate, we conducted a cross-sectional survey study. Our questionnaire contains 28 questions, all of which have been approved by 4 experts. Data were collected from Mahidol University International Demonstration School (MUIDS) students who aged between 15 and 18 years old using an online survey, Google Forms. A total of 245 students participated in the study and completed the survey. To determine the correlation between colours and stress levels, we used Statistical Product and Service Solutions version 27.0 (SPSS) for data analysis. Pearson's correlation test revealed that there is no significant correlation between colours and stress levels. Although we did not find any correlation, we suspected that there might be other possible factors such as cultures, personality and situational factors that play a significant role in developing stress. Moreover, colours also have different meanings in different cultures. Therefore, more scientific research is required to gain a better understanding of colour psychology.
\end{abstract}

KEYWORDS: Colours, Stress, International School Teenagers

\section{LITERATURE REVIEW}

Colour is one of the common mediums for communicating and expressing emotions in individuals ${ }^{1}$. Considering the dimensions of colours, there are effects that could affect individuals' emotions and physical worlds, as well as, some side effects of depression and objectionable effects. There are two groups of colours that can be used to distinguish anxiety and mentality of individuals, namely cold and warm. Warm colours can be interpreted as provocative and inviting ${ }^{2}$ whereas cold colours represent calm emotions. Stress varies among each individual's personality, personal experiences, and their personal characteristics such as age and gender.

\section{INTRODUCTION}

Stress in people has been exponentially increasing since the pandemic of COVID-19 began to spread throughout the world, affecting several countries harshly. Moreover, it directly affects the physical and mental health of people, especially adolescents. Stress in young adults tends to build up as they grow up, since more responsibility has to be taken, and more pressures are given when becoming an adult. As stress in an individual starts to increase, it will keep piling up if they do not have a way to relieve their stress correctly, and this may lead to other possible mental illnesses such as depression. Colour therapy, also known as chromo therapy, is an alternative remedy that uses colours and light to treat physical or mental health by balancing the body's energy centers, also known as chakras ${ }^{3}$. Each colour and its mood tone tend to express people's emotions or how they think or feel. This also depends on the types and tones of the colours that were shown or given. Today, there are different ways for people to cope with stress, such as music therapies ${ }^{4}$ and sport therapies ${ }^{5}$, yet colour therapy has not been well known in the perspective of the new generations. This poses a challenge to understand how colour therapy works and how colour therapy helps understand the stress in teenagers through colours around us. 


\section{International Journal of Current Science Research and Review}

ISSN: 2581-8341

Volume 04 Issue 03 March 2021

DOI: 10.47191/ijcsrr/V4-i3-13, Impact Factor: 5.825

IJCSRR@ 2021

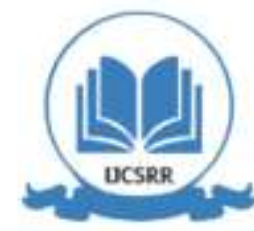

www.ijcsrr.org

Dr. Rudolf Steiner, a philosopher, stated that "there is a relationship between art and human's souls which is why colours could affect our feelings." His work was also inspired by Goethe's Colours Theory about the nature of colours, colour spectrums and how these colours are perceived by humans. In other words, how different colours impact a human's mood and emotions. Steiner applied his idea combining with Goethe's to establish a therapy and therapeutic painting ${ }^{6}$.

According to the transactional model of stress and coping ${ }^{7}$, there are four major types of stress: time stress, anticipatory stress, situational stress, and encounter stress. Each type has its own nuances, drawbacks, and even benefits. Time stress involves the feeling of being so prevalent that there is not enough time each day. This type of stress usually occurs when the deadline is near. Anticipatory stress is one of the most insidious forms of stress because it can be constant. Situational stress could also be a serious condition, "Adolescent mental health is often overlooked," said Thomas Davin, UNICEF Representative for Thailand". "Most adolescents do not have access to information that can guide them to effectively manage their emotions or mental health." A UNICEF-led survey released in April 2020 found that for more than 7 in 10 children and young people in Thailand, COVID-19 pandemic was affecting their mental health, causing stress, worry and anxiety. What worried them the most was the uncertainty of their family's financial status, followed by the uncertainty about their education and future employment. Another study by Chulalongkorn University, professor Sufeeya Jeh-arong, has stated that colours with cooler tones could help reduce stress in people ${ }^{9}$. The cool tone colours symbolise peacefulness, and on the other hand whether cool colours could also represent the feeling of sadness in people who chose them. This research aims to explore the correlation of colours therapy and stress among international school students in Bangkok, the capital city of Thailand.Since it is unclear colours could affect adolescents mental health, this research is that if colours therapy is put into use, then the students will have better mental health status.

\section{METHODOLOGY}

The questionnaire consisted of 28 questions; all of which were designed according to the established research from Chulalongkorn University about colour therapy and the connection of tone of the colours which could express the stress in people and the Thai Stress Test $(\mathrm{TST})^{10}$. There were two sections in total in the questionnaire; (1) stress and (2) the correlation of the difference in the colours tones that the participants would choose. The sampling participants were from Mahidol University International Demonstration School (MUIDS). The number of students in the school was 742 students in total. Data were collected with Taro Yamane ${ }^{11}$ calculation using more than 222 participants within the errors of 5 percent. The survey form had been sent out by posting the link in Instagram and passed

to other students inside the school.

We obtained 245 responses, which were more than we expected. Statistical Product and Service Solutions version 27.0 (SPSS) was used to analyse the data. The questionnaire contained multiple choices with Likert scale. Each statement was measured on a scale from 1 (not at all) to 5 (really care). The response was to express how much they agreed or disagreed with a particular statement. Then Item-Objective Congruence (IOC) was used to screen the item quality. Then the Cronbach alpha ${ }^{12}$ was calculated and the score was 0.811 which was widely acceptable.

\section{RESEARCH QUESTIONS}

1. Does colour define stress in teenagers?

2. What is the relationship between colours and stress within teenagers?

\section{DATA ANALYSIS}

The Statistical Product and Service Solutions version 27.0 (SPSS) was used to determine the correlation of the response data. There was a five point Likert scale for each question starting from not at all to really care. The relationship between colours and stress was determined by Pearson's correlation test, and the results indicated that they did not correlate. 


\section{International Journal of Current Science Research and Review}

ISSN: 2581-8341

Volume 04 Issue 03 March 2021

DOI: 10.47191/ijcsrr/V4-i3-13, Impact Factor: 5.825

IJCSRR@ 2021

Www.ijcsrr.org

\section{RESULTS AND DISCUSSIONS}

Table 1: General information about participants

\begin{tabular}{|c|c|c|}
\hline \multirow{4}{*}{ Age } & 15 & Valid Percentage (\%) \\
\cline { 2 - 3 } & 16 & 13.1 \\
\cline { 2 - 3 } & 17 & 25.7 \\
\cline { 2 - 3 } & 18 & 43.3 \\
\hline \multirow{4}{*}{ Gender } & Male & 18.0 \\
\cline { 2 - 3 } & Female & 26.1 \\
\cline { 2 - 3 } & LGBTQ+ & 65.3 \\
\cline { 2 - 3 } & Prefer not to say & 5.7 \\
\hline \multirow{4}{*}{ Grade/Year Group } & Grade 10/Year 11 & 2.9 \\
\hline \multirow{3}{*}{ Medical Condition (s) } & Grade 11/Year 12 & 24.9 \\
\cline { 2 - 3 } & Grade 12/ Year 13 & 41.6 \\
\cline { 2 - 3 } & Have & 33.5 \\
\cline { 2 - 3 } & Do not have & 13.9 \\
\hline \multirow{3}{*}{} & & 86.1 \\
\hline
\end{tabular}

Table 2: Descriptive Statistics (Mean and Standard Deviation)

\begin{tabular}{|c|c|c|c|}
\hline \multicolumn{2}{|c|}{ Mean } & Std. Deviation & N \\
\hline Colours & 3.4414 & 0.5773 & 245 \\
\hline Stress & 2.9253 & 0.5302 & 245 \\
\hline
\end{tabular}

Table 3: The Correlation between Art and Stress

\begin{tabular}{|c|c|c|c|}
\hline \multicolumn{2}{|c|}{} & colours & Stress \\
\hline \multirow{4}{*}{ Colours } & Pearson Correlation & 1 & 0.056 \\
\cline { 2 - 4 } & Sig. (2-tailed) & - & 0.381 \\
\cline { 2 - 4 } & $\mathrm{N}$ & 245 & 245 \\
\hline \multirow{5}{*}{ Stress } & Pearson Correlation & 0.056 & 1 \\
\cline { 2 - 4 } & Sig. (2-tailed) & 0.381 & - \\
\cline { 2 - 4 } & N & 245 & 245 \\
\hline
\end{tabular}




\section{International Journal of Current Science Research and Review}

ISSN: 2581-8341

Volume 04 Issue 03 March 2021

DOI: 10.47191/ijcsrr/V4-i3-13, Impact Factor: 5.825

IJCSRR@ 2021

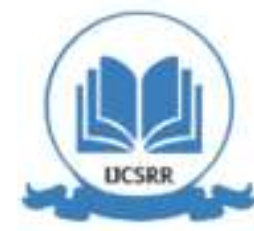

www.ijcsrr.org

Table 1 shows the general information about our participants. The majority of the age range was between the age of 16 with 25.7 percent and 17 years old with 43.3 percent of the total population. Moreover, there are more participants who are female, 65.3 percent, than male. Lastly, most of our participants do not have any medical conditions which can relate to the results we have after it had been analyzed.

Table 2 shows the mean and standard deviation of each variable. The mean of the colours was 3.4414, while its standard deviation was rounded up to 0.5773 . For stress, the mean was 2.9253 and its standard deviation was also rounded down to 0.5302 . Their means and standard deviations depend within the same population which is 245 participants.

Table 3 shows that the results did not support the hypothesis that there is a correlation between colours and stress levels of international school teenagers. There is no significance $(p<0.01)$ between the two variables. Correlation coefficients, $r=0.056$ which revealed that there are no correlation between stress and colours.

\section{CONCLUSION}

According to Table 3, colours and stress did not correlate with each other. The mean of art (3.4414) was higher than the mean of stress (2.9253). At first, we hypothesised that the mean of stress would be higher than this. To sum up our research, the result shows that there is no correlation between colours and stress. Personality and culture of the participants may be major factors that influence our results. A faculty member of the Department of Architecture, Design, and planning at the University of Sydney, has suggested that people should be wary of many claims they see about the psychology of colours. She also commented, "Many of these claims lack substantiation in terms of empirical support, exhibit fundamental flaws such as causal oversimplification and subjective validation, and may include facts presented as facts" ${ }^{13}$. Moreover, colour therapy has not been publicly accepted as a legitimate approach to stress management but instead a complementary or an alternative to typical healing techniques.

\section{REFERENCES}

1. The correlation between colours choices and impulsivity, anxiety and depression. (2016, March 13). Retrieved from https://bit.ly/2PIHsIb

2. Flanagan, L. (n.d.). How to use warm and cool colours with your home decor. Retrieved March 07, 2021, from https://bit.ly/3uVG4lH

3. DeVault, N. (2019, May 08). How colours therapy benefits people with disabilities. Retrieved March 06, 2021, from https://bit.ly/3qoUAim

4. Bussakorn Binson's HOMEPAGE. (2017). Retrieved March 07 , 2021, from https://bit.ly/3efRkDr

5. Physical activity reduces stress. (2019, December 17). Retrieved March 07, 2021, from https://bit.ly/3c2ZLiM

6. Art therapy in perspectives of Human Philosophy (ศลิ ปะบาำ บัดในมุมมองของมนุษยปรัชญา) (2017, October 17). Retrieved March 07, 2021, from https://syr.us/V1M

7. 4 types of stress: Do you know what is CAUSING YOURS? (2020, November 02). Retrieved March 07, 2021, from https://bit.ly/3qjMqrj

8. World mental health day 2020. (2020, October 10). Retrieved March 07, 2021, from https://uni.cf/3efmn2c

9. Association of colors and mood-tones of late adolescents and early adults. (2004). Retrieved February 15,2021, from https://bit.ly/3cnP0rF

10. Thai stress test, TST. (2011). Retrieved February 15 , 2021, from https://bit.ly/3tUGGqr

11. Research Methodology. (n.d.). Retrieved from https://bit.ly/3v4cme2

12. What is Coefficient Alpha? An Examinations of Theory and Applications. (1993). Retrieved from https://bit.ly/38hhn9C

13. Can colours affect your mood and behavior? (2020, May 28). Retrieved March 06,

14. 2021, from https://bit.ly/3kRRQsw

Cite this Article: Jiraporn Jensuriyarkun, Tita Matrot, Patreeya Janyasan, Dr. Ponlkrit Yeesin(2021). Association of Colours and Mood Tones That Could Define Stress among International School Students in Bangkok. International Journal of Current Science Research and Review, 4(3), 242-245 